\title{
Os percursos da cura: abordagem antropológica sobre os itinerários terapêuticos dos moradores do complexo de favelas de Manguinhos, Rio de Janeiro
}

\section{| ${ }^{1}$ Jaqueline Ferreira, ${ }^{2}$ Wanda Espírito Santo |}

Resumo: O presente artigo discute os dados da pesquisa realizada em 2008, no complexo de favelas de Manguinhos, no Município do Rio de Janeiro, sobre os itinerários terapêuticos da população local. Compreendemos por itinerários terapêuticos os caminhos percorridos pelo indivíduo na busca de solução para os seus problemas de saúde. Buscamos identificar até que ponto esses percursos são ordenados por esquemas simbólicos ou pela disponibilidade dos recursos. O método utilizado foi o qualitativo centrado na técnica de entrevistas semidiretivas seguindo um roteiro etnográfico. Foram entrevistados em média três moradores de cada comunidade de Manguinhos, perfazendo um total de 26 entrevistas. Nos resultados da pesquisa, observamos que a oferta de serviços é heterogeneamente distribuída, sendo ela mesma fator gerador de desigualdades na doença. As estratégias diversas revelam que os conhecimentos e práticas desses indivíduos são construídos de e por experiências diversas, em situações biográficas determinadas, e que não há um modelo único de itinerário terapêutico. As "maratonas" urbanas percorridas pela população local denunciam a urgência do Estado em colocar em prática políticas mais justas com um acesso completo à assistência à saúde, garantindo assim o respeito aos direitos.

> Palavras-chave: itinerários terapêuticos; cura; religião; acesso à saúde; serviços de saúde.
${ }^{1}$ Professora adjunta do Instituto de Estudos em Saúde Coletiva da Universidade Federal do Rio de Janeiro. Endereço eletrônico: jaquetf@gmail.com

${ }^{2}$ Pesquisadora do Centro de Saúde da Escola Germano Sinval Farias da Escola Nacional de Saúde Pública da Fiocruz. Endereço eletrônico:wandaes@ gmail.com

Recebido em: 12/10/2010 Aprovado em: 29/07/2011. 


\section{Introdução}

O presente artigo propõe-se a discutir os dados de uma pesquisa realizada no ano de 2008 sobre os itinerários terapêuticos dos moradores do complexo de favelas de Manguinhos, zona norte do município do Rio de Janeiro ${ }^{1}$.

Itinerários terapêuticos (IT), conceito proposto pelo antropólogo francês Augé (1984), podem ser definidos como o caminho percorrido pelo indivíduo na busca de solução para seus problemas de saúde, diante de uma heterogeneidade de recursos. Segundo essa perspectiva, o aspecto central é o ponto de vista dos atores sobre a maneira como se dá sua experiência de doença e cura. O conceito, que inicialmente foi aplicado às sociedades tradicionais africanas, é atualmente incorporado por pesquisadores de complexos urbanos. Fainzang (1985), por exemplo, ao comparar percursos de cura no contexto das sociedades tradicionais africanas e urbanas francesas, observa que em ambas as sociedades a doença é interpretada como desordem social, e que as terapêuticas seguidas obedecem antes a essa interpretação do que à biomédica.

Alves e Souza (1999) realizaram uma importante revisão da literatura nacional e internacional sobre IT, e mostram que os estudos sobre o assunto devem levar em conta as representações simbólicas do processo de doença do indivíduo, bem como os macroprocessos socioculturais. Nesse sentido, abordagens como a de Massé (1985) dão conta da complexidade da questão, ao referirem que os IT sofrem a influência de múltiplas variáveis de ordem situacional, social, psicológica, econômica e outras: "A procura de cuidados está condicionada tanto pelas atitudes, os valores e as ideologias quanto pelos perfis de doença, o acesso econômico e a disponibilidade de tecnologias" (p. 330).

Vários estudos evidenciam as sérias dificuldades de acesso à saúde, que são determinadas por obstáculos econômicos, geográficos e culturais, das populações de baixa renda (TRAVASSOS et al., 2000; LIMA et al., 2002). Da mesma forma, Castro e Farmer (2003) apontam que a pobreza e as desigualdades sociais aumentam a probabilidade de ocorrer doença e morte, ao restringirem o acesso aos serviços de saúde, nos quais até mesmo o advento de terapias eficazes pode acrescer o grau de desigualdade, se elas ficarem restritas a uma classe privilegiada. Segundo os autores, o grande índice de doenças mal 
tratadas nos países pobres é resultante principalmente das condições estruturais

de pobreza, das consequências tanto da globalização quanto de políticas de saúde internacionais. Assim, melhorar a saúde dos indivíduos só será possível à medida que forem eliminadas as próprias condições da desigualdade.

As considerações teóricas acima são fundamentais para nosso estudo com os moradores de favelas pertencentes ao Complexo de Manguinhos. Tais perspectivas apontam que não há um padrão nos percursos de cura, pois eles são influenciados por fatores tanto de ordem socioeconômica quanto simbólicos. Assim sendo, é necessário levar em conta a oferta e a facilidade de acesso aos serviços de saúde, bem como os elementos culturais que organizam a vida coletiva das populações de baixa renda. Esses aspectos são dinâmicos e situacionais, e podem variar de acordo com a trajetória biográfica do indivíduo e com seu ambiente de vivência e convivência.

A região de Manguinhos, como outras áreas faveladas do Rio de Janeiro, espelha as mudanças de ordem econômica e social ocorridas no país. Ao longo do tempo, o processo de migração, o crescimento urbano acelerado e o empobrecimento das camadas populares têm sido elementos que determinam a conformação dessa área. Sua população é de aproximadamente 50 mil habitantes, espalhados em $490.000 \mathrm{~m}^{2}$, com cerca de 12 mil domicílios, que formam 13 comunidades. Esses domicílios são ocupados, em média, por 3,7 habitantes. Trinta por cento das construções são consideradas irregulares, de risco ou provisórias. A população é jovem/adulta, com 54\% na faixa etária de 15 a 49 anos. A renda per capita está em torno de menos de um salário mínimo, e $45 \%$ da população economicamente ativa se encontra no mercado informal de trabalho (BODSTEIN, 2001).

$\mathrm{O}$ fato de as comunidades de Manguinhos serem cobertas pelo Programa de Saúde da Família (PSF) também permite avaliar as condições de acesso a esse programa. No local encontram-se igualmente uma igreja católica, vários templos pentecostais e um centro de candomblé, o que permite discutir a utilização de outras alternativas terapêuticas. Assim, quais são os fatores que influem na adesão ou não adesão ao recurso biomédico: confiança no terapeuta, custo do tratamento, proximidade, serviços oferecidos? Da mesma forma, supondo que haja facilidade de acesso aos serviços e profissionais de saúde da biomedicina, quais são os valores atribuídos às alternativas terapêuticas? 


\section{Metodologia}

Esta pesquisa, de cunho qualitativo, serviu-se da técnica da entrevista etnográfica. A entrevista etnográfica tem relevância na medida em que leva em conta a história do local, apoiando-se na observação e guiando-a. Segundo Beaud (1995), as entrevistas etnográficas levam em conta a interação entre entrevistador e entrevistado, na qual a observação da cena social (espaços e pessoas) fornece elementos para sua interpretação.

Assim, buscamos realizar nossas entrevistas no local de moradia das pessoas, de forma que pudéssemos observar as condições de vida, relações familiares e de vizinhança, dando lugar a nossas impressōes sobre cada tema do roteiro. $\mathrm{O}$ tom de voz, os silêncios, lágrimas e risos dos entrevistados evidenciavam as emoções suscitadas, ao rememorar seus episódios de doença e seus percursos de cura, dando-nos elementos para interpretar os dados a partir do ponto de vista deles ${ }^{2}$. O fato de uma mãe de santo ter "recebido a entidade" 3 durante a entrevista e, a partir daí, questionar o objetivo de nossa pesquisa, colocou em questão nosso papel de pesquisadores e nos fez refletir sobre questôes da autoridade religiosa para nossos informantes.

Foram realizadas três ou mais entrevistas em cada comunidade do Complexo de Manguinhos, totalizando 26 entrevistas. Os entrevistados deviam ter mais de 18 anos, sem considerar o sexo, ser moradores do local por mais de cinco anos e residir em comunidade atendida pelo PSF, não sendo necessário que utilizassem o programa. A seleção ocorreu a partir de referências dos agentes comunitários de saúde, contatos com organizações não governamentais, instituições religiosas e outros serviços existentes no local.

Os dados buscados foram: estrutura familiar residencial, renda, trabalho, escolaridade, formas de lazer e sociabilidade, trajetória familiar (migração e rede familiar existente em Manguinhos), relação com sua comunidade (problemas identificados, satisfação ou não por residir no local), representações sociais de doença, a fim de compreender, no contexto e no modo de vida da população estudada, fatores que pudessem influenciar seus percursos terapêuticos. Os casos apresentados referem-se aos que os entrevistados relataram como os mais significativos na sua experiência de busca de tratamentos. 
A pesquisa foi aprovada pelo Comitê de Ética em Pesquisa da Escola Nacional de Saúde Pública Sergio Arouca, da Fundação Oswaldo Cruz, e todos os participantes assinaram um termo de consentimento informado. Os nomes usados são fictícios, a fim de preservar o anonimato.

\section{Pessoas diferentes, realidades semelhantes}

Nossos entrevistados compartilham o modo de vida e as condições ambientais: em todas as comunidades, o saneamento básico é deficiente, há moradias de alvenaria e barracos, pequenas casas de comércio, vários templos religiosos (sobretudo pentecostais e igrejas católicas). Muitos entrevistados moram há vários anos na região, e a prevalência da moradia própria provém de invasão.

A grande maioria dos entrevistados era composta de mulheres (23) e donas de casa (17), o que facilitava sua disponibilidade para participar da pesquisa. Sobretudo as mulheres mais idosas apresentavam tendência maior à busca de recursos terapêuticos alheios à biomedicina, especialmente religiosos, enquanto os homens (3) referiram preferir o recurso biomédico em situaçôes identificadas como doenças. As idades foram variáveis, mas a maior concentração (17) deu-se na faixa etária entre 30 a 59 anos, e o restante (9), na faixa de 60 a 85 anos. A cor prevalecente foi não branca, uma vez que eles se autorreferiram principalmente como de cor morena e escura. Grande parte dos entrevistados tem o ensino fundamental incompleto (19), o que confirma a dificuldade de acesso escolar dos grupos populares. Quatro entrevistados referiram ser analfabetos.

A renda familiar de grande parte das famílias concentrava-se entre um e dois salários mínimos. Das três pessoas entrevistadas com renda inferior a um salário mínimo, duas apontavam como única fonte de renda o programa Bolsa Família. Conforme já referido, a maioria das mulheres entrevistadas eram donas de casa e os homens, aposentados. As mulheres que trabalhavam exerciam as atividades de auxiliar de limpeza (1), comerciária (3) e diarista (2).

Nossa pesquisa vai ao encontro do estudo clássico de Boltanski (1984), segundo o qual, quanto menores forem a renda e a escolaridade, maior será o tempo de espera para buscar os recursos biomédicos, devido ao impedimento das atividades laborais. Além disso, as dificuldades de locomoção ou o receio de arcar com tratamentos e exames não cobertos pelo SUS dificulta igualmente o acesso 
a esse recurso, o que, consequentemente, agrava o estado de saúde da pessoa. Esses marcadores confirmaram igualmente que, quanto piores são as condições econômicas e a escolaridade, mais difícil é o contato com os profissionais de saúde, tendo em vista o não domínio de códigos da biomedicina e da linguagem das classes dominantes.

A situação familiar correspondia à de oito a duas pessoas em cada domicílio, e prevalecia a situação de conjugalidade. Os homens viviam sozinhos, e relataram recorrer à ajuda de vizinhos e amigos em caso de doença, se isso fosse necessário. Esse aspecto é relevante, uma vez que as redes familiares e comunitárias são fundamentais em casos de doença (ALVES; SOUZA, 1999).

A procedência dos moradores era predominantemente da região Nordeste (14), sobretudo da Paraíba (9). O relato predominante sobre o motivo da mudança para o Rio de Janeiro foi a necessidade de buscar trabalho e melhores condições de vida, incluindo-se o acesso aos serviços de saúde. Beatriz, 65 anos, por exemplo, saiu de Pernambuco para morar em Manguinhos há 34 anos, devido à falta de acesso à consulta médica, que só era possível após três horas de carro: "A gente só ia no médico quando tava morrendo". Outros estados de origem eram Minas Gerais (3), Belém (1) e Espírito Santo (1). Somente uma pequena parcela (7) provinha de outras cidades do Rio de Janeiro. A maior parte era de origem urbana (20).

A grande maioria dos entrevistados possuía parentes habitando em Manguinhos, o que estabelece uma rede densa de solidariedade (BOTT, 1976) e, assim, proporciona conforto e cuidados, em casos de doenças, ou auxílio no transporte e acompanhamento aos serviços de saúde. Os que possuíam parentes distantes contavam com o apoio de vizinhos nesses casos. Foi o caso da mãe de santo Olívia, de 76 anos, que tinha dois filhos vivendo em outras cidades. Olívia morava em um prédio próprio, onde abrigava várias pessoas e famílias. Nesse espaço, também se localizava seu terreiro. De acordo com ela,

Às vezes, as pessoas vêm pedir para morar, eu arrumo um canto. Às vezes, não têm família. Como eu também não tenho saúde, quando tenho que ir no médico e um não pode me levar, o outro leva.

Olívia era um exemplo de como as redes de ajuda mútua se estabelecem em função dos espaços de convívio. Maria, proprietária de um pequeno comércio de 
alimentos, fazia igualmente de sua venda um espaço de sociabilidade. Durante nossa entrevista, as vizinhas se aproximavam para participar e opinar sobre o assunto. Outro exemplo é o de Márcio, que morava na entrada da comunidade Parque Carlos Chagas. Ele passava o dia sentado na frente de sua casa, e assim podia conversar com quem entrava ou saía da comunidade. Essas redes de convivência eram igualmente a principal forma de lazer para a grande maioria dos moradores do Complexo de Manguinhos. Como não poderia deixar de ser, as informações sobre doenças, tratamentos e serviços de cura disponíveis eram também trocadas nesses espaços.

A grande maioria dos entrevistados referiu estar satisfeito de morar em Manguinhos. A principal ressalva foi a violência. Em muitas situações, as entrevistas foram adiadas, em virtude de "conflitos na comunidade": "Não, hoje tá brabo, não entra e não sai ninguém”, alertavam-nos os agentes comunitários de saúde. Em uma ocasião, durante nossas entrevistas, ouvimos tiros próximos. Os moradores riam de nosso medo evidente. Comentários do tipo: "Tiro tem em toda a parte" nos mostravam que a banalização da violência é uma estratégia para suplantar as afliçôes provocadas por ela. Por outro lado, a impossibilidade de transitar nos momentos de conflito, sobretudo em casos de doenças, que levava os moradores a faltar a consultas marcadas com dificuldade, foram relatadas com angústia:

Tinha consulta marcada em Bonsucesso, mas, com esses tiroteios, não dá pra sair de casa (Maria de Fátima, dona de casa, 29 anos).

Da mesma forma, eles deixavam claro seu descontentamento em relação à imagem negativa que isso acarretava para sua comunidade.

Enfim, estar na "linha de fogo", em meio à "bandidagem" e ao tráfico de drogas, em brigas com vizinhos, não haver espaço para as crianças brincarem, nem saneamento foram problemas citados por esses moradores. No entanto, a ideia de mudança de comunidade não faz parte do desejo da maioria deles:

Gosto daqui, pois não tenho condições de morar em outro local, e, favela por favela, prefiro aqui (Silvio, 75 anos).

Assim, o relativo acesso ao trabalho, aos serviços de saúde, à escola e aos meios de transporte, e os vínculos afetivos na comunidade, que proporcionam ajuda e apoio em caso de necessidade, amenizam relativamente os problemas de morar em uma região violenta como Manguinhos. 


\section{A pluralidade de itinerários terapêuticos}

Conforme já assinalamos, estudar os IT implica para o pesquisador ter olhar e percepção ampliados sobre a questão, tendo em vista os vários fatores de ordem situacional e relacional que o influenciam (GERHARDT, 2006).

$\mathrm{Na}$ comunidade pesquisada, os remédios caseiros (chás, banhos de ervas e xaropes) figuravam como a primeira escolha, diante dos sintomas identificados como doença. Os remédios alopáticos mais citados foram os analgésicos ${ }^{4}$, mas os calmantes (remédios para os "nervos") também foram bastante citados. Não menos importante como opção terapêutica era o recurso à benzedeira, à benção do padre ou à oração do pastor:

Quando estou triste, tomo um chá de cidreira, pego a Bíblia e faço uma oração. Converso com uma amiga, e não preciso recorrer a calmantes (Ana, 54 anos, praticante da religião "Testemunhas de Jeová”).

Observamos que a religião era muito presente no cotidiano das mulheres entrevistadas. A maior parte referiu pertencer à religião católica (11) e as demais, à evangélica (2), Testemunhas de Jeová (1) e candomblé (1). Os homens entrevistados negaram qualquer vínculo religioso. No entanto, muitas das católicas entrevistadas relataram frequentar outras religiōes, sobretudo evangélica, Testemunha de Jeová e umbanda. Uma entrevistada da religião evangélica refere ser também simpatizante da Testemunha de Jeová, isto é, diferentes crenças são acionadas, de acordo com a situação e com os significados que elas abrangem.

Assim, a religião assume grande relevância para as populações de baixa renda, inscreve-se em seu cotidiano como importante recurso de cura (RABELO, 1993). De acordo com Luz (2007), nas representaçóes populares da doença, a imagem de ruptura de equilíbrio espiritual aparece frequentemente como causadora do adoecimento. A cura dependerá de resgatar esse equilíbrio. Dessa forma, os sistemas de cura que privilegiam esse aspecto têm grande aceitação nessa faixa da população.

Outra lógica que regia essas opções era a classificação das doenças em leves ou graves. $\mathrm{O}$ médico raramente era procurado diante dos primeiros sintomas. Para os problemas considerados leves, a automedicação e os remédios caseiros eram sempre a primeira escolha, e o recurso biomédico restringia-se a situaçôes identificadas como mais graves, ou diante da impossibilidade de trabalhar 5 . 
De fato, encontram-se à disposição da população diferentes recursos

terapêuticos (recursos caseiros, religiosos e biomédicos), com diferentes explicaçôes para o sofrimento. Assim, nesse processo de escolhas terapêuticas, a recorrência simultânea a diferentes recursos, comumente interpretada pelos profissionais de saúde como incoerente ou paradoxal, não se justifica, na medida em que vários fatores de ordem situacional e relacional influem nas escolhas terapêuticas pelo indivíduo doente. Segundo Rabelo (1993, p.323),

a existência de visões discordantes - e até mesmo contraditórias - sobre a questão terapêutica evidencia que tanto a doença como a cura são experiências intersubjetivamente construídas, em que o paciente, sua família e aqueles que vivem próximos estão continuamente negociando significados.

Ainda de acordo com a autora, as escolhas se viabilizam em um grande campo de possibilidades culturais, no qual os indivíduos estão constantemente negociando significados. Não existem fronteiras entre as diferentes alternativas.

Isso é o que percebemos em nossa pesquisa, pois um indivíduo pode acionar diferentes recursos de cura para a mesma ou diferentes perturbaçôes concomitantemente, que funcionam em uma lógica de complementaridade em relação a sua eficácia ${ }^{6}$. Ana, por exemplo, 54 anos, praticante da religião Testemunhas de Jeová disse que para "todos os problemas da vida, tem que procurar primeiro Deus, para orientar os médicos", e Marlene, 51 anos, praticante da religião católica, declarou que "Deus dá sabedoria aos médicos. Então, a gente tem que procurar o médico quando está doente”. Dessa maneira, os recursos não entram em conflito, à medida que os médicos estão sujeitos às leis divinas e são por elas orientados na cura de seus pacientes. Por outro lado, nossa pesquisa também corrobora autores que apontam como é feita a distinção entre doença material e doença espiritual pelos grupos de baixa renda (MONTERO, 1985; ROCHA, 2000). É o caso de Maria da Graça, 50 anos, dona de casa, que acreditava que o problema de sua neta, diagnosticado pelo médico como neurológico, fosse mais espiritual, tendo como tratamento "tomar um óleo ungido, uma água abençoada".

No entanto, as condições socioeconômicas também determinam as escolhas, como evidencia o relato de Mariana, 57 anos, que recorria a vários tratamentos preconizados pela Igreja Pentecostal (orações, ervas), porque eram mais acessíveis 
do que "os tratamentos caros indicados pelo médico". De acordo com Valla et al. (2005), o fato de as populações de baixa renda procurarem as religiōes populares pode sinalizar tanto as alternativas simbólicas para resolver os problemas de saúde quanto uma forma de se defender da exclusão dos serviços oficiais.

Assim, foi recorrente no relato de nossos entrevistados a busca concomitante pelo recurso biomédico e religioso, influenciada tanto por questôes simbólicas como socioeconômicas.

\section{Recurso à biomedicina: "maratonas" urbanas na busca por assistência}

Diversas variáveis influem no consumo dos recursos biomédicos. Travassos et al. (2000), por exemplo, observaram como a utilização dos serviços de saúde aumenta de acordo com a renda, escolaridade e cor (indivíduos brancos os utilizam mais), evidenciando como a biomedicina está em consonância com uma camada social dominante. Outro estudo (KASSOUF, 2005), ao comparar a área urbana com a rural, baseando-se nos estudos da Pesquisa Nacional por Amostra de Domicílios (PNAD) em diversos estados brasileiros, concluiu que, na área urbana, os indivíduos buscam mais o recurso biomédico, tanto pela sua maior disponibilidade em relação à zona rural, como pela posse de planos de saúde. Isso demonstra que a facilidade de acesso e os recursos financeiros são determinantes nessa procura.

Por outro lado, não devemos igualmente esquecer que as necessidades de saúde da população são muitas vezes determinadas pelo poder da cultura biomédica, uma vez que o indivíduo aprende a reconhecer os sintomas e sinais, de acordo com os parâmetros do poder e por meio de seu contato com os profissionais de saúde (BOLTANSKI, 1984; CAMARGO, 2005).

Nossos entrevistados apresentavam ampla gama de doenças e recorriam a diferentes serviços de saúde 7 . Os serviços citados chamam a atenção sobre a heterogeneidade de serviços e sua ampla distribuição geográfica, e nos faz refletir sobre o tipo de serviço buscado em relação a seu nível de atenção, sua acessibilidade e a lógica que rege essas escolhas ${ }^{8}$. 


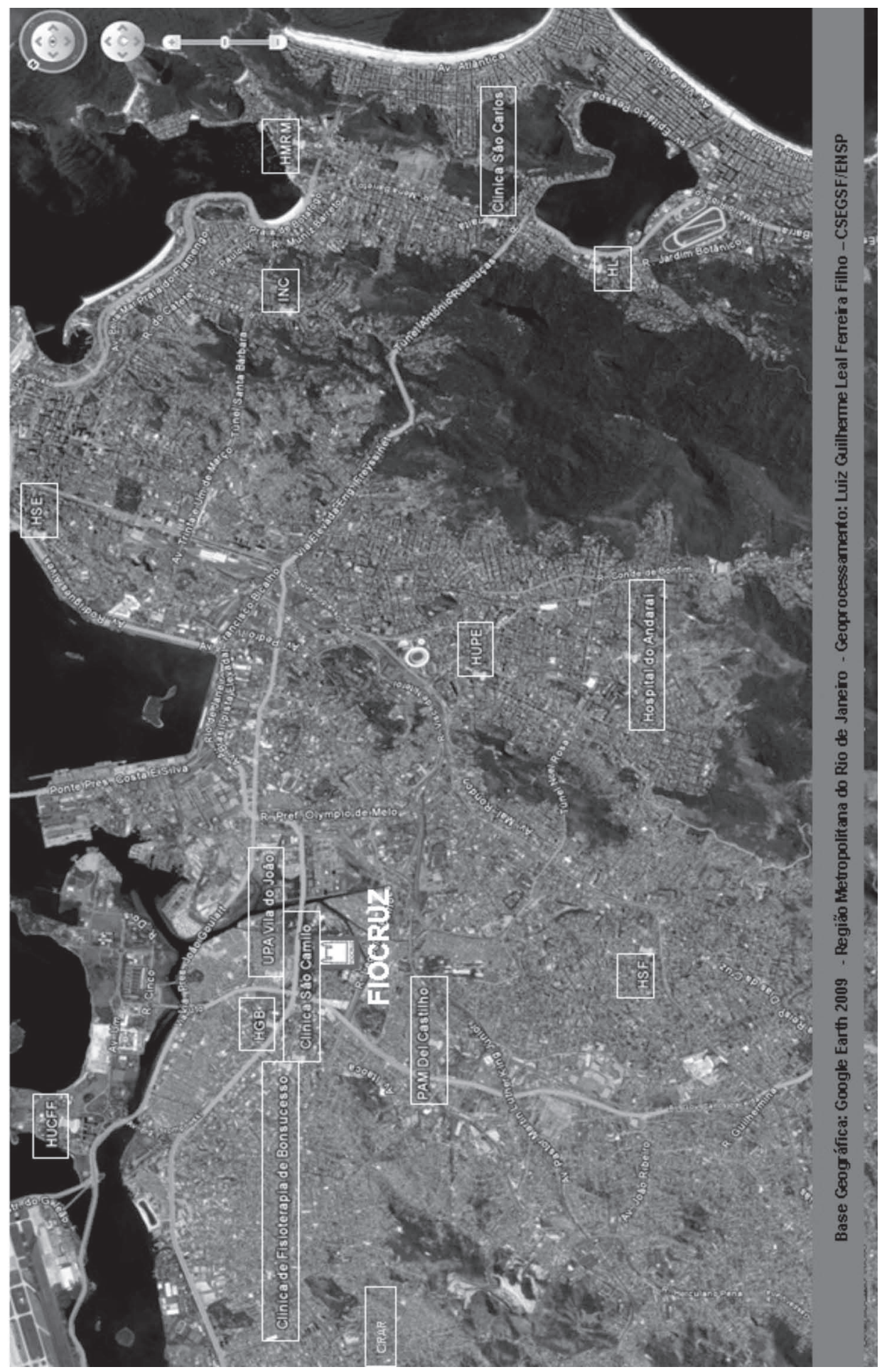


Dois aspectos que nos chamam atenção são o consumo de vários serviços concomitantemente, na lógica da disponibilidade, e a necessidade de serviços especializados ou não. Um exemplo é o de Beatriz, 65 anos, dona de casa, que sofria de hipertensão arterial, diabetes, artrose e artrite. Sua filha trabalhava em uma clínica no bairro Saens Peña, com direito a convênio com o sindicato para a realização de consultas especializadas. Por meio desse convênio, ela realizava fisioterapia em outra clínica, no bairro da Tijuca. Já no PSF Manguinhos, ela fazia acompanhamento do diabetes e da hipertensão a cada seis meses.

Assim, a busca de tratamentos é realizada de acordo com a facilidade de acesso, e não conforme os princípios do PSF de que o paciente seja acompanhado integralmente e sempre pela mesma equipe de saúde. Mesmo que a relação médico-paciente seja boa, como é o caso de Beatriz: "Eu adoro o meu médico aí no posto. Ele é bem atencioso", ela busca recursos conforme a facilidade e a disponibilidade.

Outro dado relevante foi o uso das emergências como porta de entrada do serviço de saúde. Maria de Fátima justificou por que preferia a emergência do Vieira Souto aos postos de saúde:

Meu filho tem problema de bronquite e quando ele fica mal eu fico desesperada. Daí eu vou na emergência. Chego lá e eles me dizem: procura o postinho. Que postinho, eu digo! Isto aqui é caso de emergência!. Vou na emergência na cidade: Miguel Couto ou Souza Aguiar. Eu pego quatro conduções, mas prefiro, por que lá eu sou atendida, eles fazem exame e tudo. É longe, mas eu prefiro! (Maria de Fátima, 49 anos, dona-de-casa)

Isso mostra que os critérios estabelecidos nesses casos são a certeza de ser atendido e o menor tempo de espera no local, mesmo que o dispêndio de tempo para chegar ao local seja grande. Nesse aspecto, não faltam queixas sobre a longa espera das consultas agendadas nos postos de Atenção Primária.

Uma filha minha teve dengue. Ficou mal. Foi na UPA ali na Vila do João. O povo aqui tá desistindo do postinho e indo para lá. Por que lá é atendido. Apesar que agora está tendo aquele problema: demora um pouco. Mas é atendido, fazem RX. A minha filha foi lá e piorou, piorou...Chamaram a ambulância e levaram ela para o Hospital Geral (de Bonsucesso). Lá atenderam na hora porque chegou de ambulância, senão, não adianta chegar lá passando mal, que é difícil. (Márcia, 43 anos, auxiliar de limpeza).

Todos os médicos do Andaraí foram muito bons para ela. Ela passou mal... teve uma noite lá que ela passou mal. Tava tendo um princípio de uma AVC [Acidente Vascular Cerebral]. As enfermeiras correram, deram todos os remédios. Quando a médica veio já tava tudo controlado. Colocaram balão de oxigênio, essas coisas todas...então eu não tenho o que me queixar do Andaraí, dos médicos de lá e nem agora do hospital 
Pedro Ernesto, nem do Piquet Carneiro, que continuou tratando dela. E ele falou, olha qualquer coisa que acontecer, não precisa marcar. Vem diretamente pra cá que a gente vai atender a senhora. Então sobre isso eu tô tranqüila. Porque tem hospital que depois que o paciente tem alta, você tem que voltar ao hospital pra marcar. Se der algum problema você tem que voltar pra fila, marcar, esperar um mês pra vim se tratar. (Flaviana, 83 anos, dona-de-casa)

No que se refere ao PSF de Manguinhos especificamente, muitos entrevistados referiram que frequentam o posto, mas desconhecem o PSF: "Nunca ouvi falar"; "Não, não sei se tem aqui". Por outro lado, o posto é muito criticado pelos usuários: "Se o meu médico não estiver, não pode ser com outro" (Ana, 54 anos, dona de casa); "Se a gente não estiver grávida, não é atendida" (Irene, dona de casa, 47 anos). Assim, a lógica de que um profissional deve ser responsável pela microárea, de forma a melhorar o conhecimento da população e consequentemente a qualidade do atendimento, bem como a prioridade dos programas ${ }^{9}$, é interpretada pelos moradores como uma barreira ao acesso à assistência.

Nesse sentido, os agentes comunitários de saúde são identificados principalmente como facilitadores do acesso - "Quando quero uma consulta, eu procuro ela [a agente de saúde]" (Beatriz, 65 anos, dona de casa); "O agente de saude faz visita para saber se a gente precisa de médico" (Elza, 63 anos, dona de casa) - o que evidencia que a proposta de superar o modelo medicocêntrico e o papel dos agentes comunitários de saúde não vem sendo significativa, de maneira a ser reconhecida por esses usuários.

Os aspectos acima observados nos fazem concluir que, mesmo que o PSF tenha surgido para melhorar o acesso e a qualidade do atendimento, no caso de Manguinhos, há necessidade de incremento em seu papel de promotor da saúde e maior integração dos usuários na organização dos serviços prestados. No entanto, mesmo que o processo de trabalho do PSF tenha sido criticado, os profissionais, individualmente, foram elogiados, e isso evidencia o lado positivo do programa: o envolvimento dos profissionais e o valor relacional no processo de cuidado em saúde.

A qualidade dos serviços de saúde não se refere somente ao acesso à assistência propriamente dita, mas também à competência relacional dos profissionais. Isso foi constantemente evocado por nossos entrevistados, quando avaliaram a qualidade do atendimento, que, para eles, não se resume à resolução dos problemas de saúde, e abrange "ser bem tratado" pelos profissionais, sobretudo 
pelo profissional médico. Para muitos, a atenção e a visita dos profissionais de saúde são cruciais para sua existência, pois contribuem para sua qualidade de vida. Essa dimensão do cuidado faz parte de um trabalho cotidiano, contínuo e difícil de ser quantificado. Os relatos revelam como a não valorização dos profissionais da história relatada pelo familiar ou doente pode culminar em desfechos inquietantes:

Minha mãe me levou no Hospital Geral de Bonsucesso quando tive derrame. A médica disse que era manha. Depois eu voltei lá fiquei sete dias internada (Marlene, 51 anos, dona-de-casa)

Eu tive meu neto que morreu há dois anos, Não foi atendido na hora. Ele tinha hidrocefalia, tinha válvula. A gente levou ele no Souza Aguiar. Lá o médico queria fazer um exame de urina. A minha filha já tinha um, mas o médico quis fazer outro. A minha filha ficou desesperada, pegou o ônibus e foi lá no Bonsucesso. Ele já tinha estado lá na semana antes com pneumonia. A médica lá disse: de onde você ta vindo? Do Souza Aguiar? Então tem que tomar uma injeção, vai para a fila fazer injeção. Quando ele foi para a fila, entrou em coma, foi aquela correria e ela desesperada....

Nesse caso, concordamos com Lombrail (2006), que argumenta que as desigualdades em saúde resultam também de uma assistência de má qualidade.

Nos casos de não atendimento por falta de vaga ou médico, tempo longo de espera ou descaso dos profissionais, muitos mencionaram acionar uma situação de conflito como estratégia:

Passaram um monte de dengue na frente e eu tive que 'rodar a baiana'. A gente tem que ser 'barraqueira'. Depois diz que é porque é pobre, é favelado (Márcia, 43 anos, auxiliar de limpeza).

Essa estratégia não é sem razão, tendo em vista a verdadeira peregrinação feita pelos serviços em busca de atendimento. Nesse sentido, não faltam relatos de histórias trágicas, como a de Paulina, 56 anos, dona de casa, cujo neto morreu na fila de atendimento do hospital. Sobre esse aspecto, Deslandes (2002) observa que a peregrinação do doente em busca do atendimento mostra que a fragilidade do sistema vigente, calcado no modelo médico, corresponde às variadas formas simbólicas de esses usuários viverem a violência institucional.

Outra estratégia frequentemente acionada é o uso de redes familiares ou amigos para acessar serviços de saúde. O relato de Flaviana, uma dona de casa que conseguiu internação hospitalar para sua mãe nessas condições, mostra a importância desse recurso: 
Mas o que deixou mais a gente preocupada foi que minha mãe começou a inchar.

Ela inchou inteira. Aí procuramos um hospital pra internar ela, não mais por causa da perna, mas por causa do inchaço. A gente foi ao Fernando Figueira, ao Hospital dos Servidores. A gente rodou a cidade. Não conseguimos... voltamos pro Andaraí. Porque agora é só com encaminhamento. No Andaraí, chegou lá, não tinha médico vascular. Eu falei: "Moço, eu não quero um médico vascular, eu quero um cardiologista para ver esse inchaço da minha mãe". Aí, na Emergência, o médico pedia pra bater o raio x do coração. Bateu o raio x, fez todos os exames, aí ele falou assim: "O problema é que o coração dela tá grande”. Aí deu um remédio pra ver se baixava a pressão dela. Aí um colega meu, que é segurança da Amil, tava tentando conseguir uma internação pra ela em qualquer hospital. Aí a menina que trabalha na recepção falou assim: "Eu posso ajudar? Eu tenho uns amigos que fizeram prova pra medicina e eu vou entrar em contato com eles pra ver se consigo”. Aí ela ligou pra o médico no Piquet Carneiro. Então, a gente saiu do hospital do Andaraí e fomos direto pro Piquet Carneiro. Quando chegamos lá, o médico examinou, olhou. Já tava com a papelada de internação dela todinha na mão. Ele falou: "Olha, a gente vai ter que amputar a perna dela”.

A história narrada aqui reflete um problema estrutural da saúde pública, que faz a família peregrinar por diferentes instituiçōes e só conseguir atendimento, que é garantido como direito constitucional, por meio de favores pessoais, o que não impede o desenlace trágico da amputação da perna de uma pessoa. $\mathrm{O}$ percurso e a distância total, relatados por Flaviana, perfazem $25 \mathrm{~km}$, percorridos de ônibus e táxi pela família, na busca por atendimento. Esse episódio revela aspectos da sociedade brasileira, em que os direitos aparecem como uma doação, o que já foi observado por Pinheiro e Lube Guizardi (2005). Consequentemente, no panorama da representação da sociedade, a ideia de direitos não tem seu lugar. É o que observamos quando a assistência médica é percebida como resultado da "boa vontade" ou do "bom coração" dos profissionais de saúde.

Enfim, as desigualdades sociais que assolam o país se refletem na busca e na oferta de cuidado, e isso evidencia a relação entre IT e pobreza.

\section{Concluindo}

Nosso estudo corrobora o de diversos autores que trabalham com o tema IT, e que foram citados aqui, ao tratarmos das múltiplas lógicas que regem as opções e os percursos do doente em busca de tratamento. Nesse sentido, concorrem aspectos individuais, representações socioculturais referentes à doença e aos sistemas de cura, condições socieconômicas e estruturais relacionadas à 
facilidade ou não do acesso. Cada escolha é realizada em função das situações e das explicações culturalmente aceitas pelo grupo.

No que diz respeito a nossos entrevistados, não existe um modelo único de IT e as estratégias em busca da cura são diversas. Cada alternativa tem vantagens e desvantagens, e é escolhida em função das disponibilidades circunstanciais e das experiências com doença. Os discursos e ações em relação a elas são situacionais e encontram-se impregnados de interesses, hesitaçōes, incongruências, estratégias e conflitos. Ou seja, os IT são resultados de um processo.

Às dificuldades de acesso econômico e geográfico acrescenta-se o contexto cultural. As consequências da situação econômica, espacial e ambiental em um mesmo local não são as mesmas para todos os indivíduos, pois os conhecimentos e as práticas deles são construídos em experiências diversas e por estas, em situaçôes biográficas determinadas. Somente se considerando o indivíduo em sua rede de interações se podem compreender as decisões por ele tomadas, isto é, a tentativa de solucionar seus problemas de saúde inscreve-se no cotidiano, uma vez que o enfrentamento da doença dele faz parte.

Faz parte do senso comum que a saúde está em estreita relação com a medicina. Os próprios médicos defendem essa ideia como forma de legitimação de sua competência profissional. No entanto, a saúde pública e, principalmente, o acesso à saúde estão mais relacionados às políticas públicas do que à ação dos profissionais propriamente ditos. Concordamos com Assis et al. (1993), que referem que a restrição do acesso à assistência apresenta várias dimensões: acesso seletivo (dependente da lógica do mercado), excludente (pautado no mecanismo de racionamento dos gastos) e focalizado (restrição a determinados serviços ou programas), que se complementam e se justapõem nos diferentes serviços públicos e privados, trazendo descompasso para a equidade em saúde. De fato, as "maratonas" urbanas de nossos entrevistados em busca de assistência mostram que é necessário ao Estado colocar em prática políticas mais justas, que repousem na distribuição de recursos e na ampliação dos debates sobre os determinantes de saúde. Isso permitirá acesso completo à assistência à saúde, o que garantirá verdadeiramente o respeito aos direitos dos indivíduos e possibilitará a eles desenvolver plenamente suas capacidades, sem depender de políticas compensatórias. 


\section{Agradecimentos}

Idenalva Silva de Lima e Zaira Bosco, que participaram da realização das entrevistas. ${ }^{10}$

\section{Referências}

ALVES, P.C.; SOUZA, I.M. Escolha e avaliação de tratamento para problemas de saúde: consideraçōes sobre o itinerário terapêutico. In: RABELO, M.C.; ALVES, P.C. (Org.). Experiência de doença e narrativa. Rio de Janeiro: Fiocruz, 1999. p.133-136.

AUGÉ, M. L'anthropologie de la maladie. L'Homme, Paris, v.26, n.1-2, p.81-90, 1986.

ASSIS, M.M.A.; VILLA, T.C.S.; NASCIMENTO, M.A.A. Acesso aos serviços de saúde: uma possibilidade a ser construída na prática. Ciênc. Saúde Coletiva, Rio de Janeiro, v.8, n.3, p.815-823, 2003.

BEAUD, S. L'usage de l'entretien em Sciences Sociales. Playoder pour l'entretien etnographique. Politix, 35, p.226-257, 1995.

BODSTEIN, R. Manguinhos: guia de equipamentos e iniciativas sociais. Rio de Janeiro. Fiocruz, 2001.

BOLTANSKI, L. As classes sociais e o corpo. Rio de Janeiro: Graal, 1984.

BOTT, E. Família e rede social. Rio de Janeiro: Francisco Alves, 1976. 320p.

CAMARGO JR, K.R. Das necessidades de saúde à demanda socialmente constituída. In: PINHEIRO, R.; MATTOS, R.A. (Org.). Constituição social da demanda. Rio de Janeiro: Cepesc, 2005. p.91-101.

CASTRO, A.; FARMER, P. Violence struturelle, mondialisation et tuberculose multirresistente. Anthropologie et Sociétés, Quebec, v.27, n.2, p.23-40, 2003.

DESLANDES, S.F. Frágeis deuses: profissionais da emergência entre os danos da violência e a recriação da vida. Rio de Janeiro: Fiocruz, 2002. 196p.

DOS ANJOS, J.C. O corpo nos rituais de iniciação do batuque. In: LEAL, O. (Org.). Corpo e significado. Ensaios de Antropologia Social. Porto Alegre: UFRGS, 1995. 472p.

FAINZANG, S. Pour une anthropologie de la maladie en France. Paris: EHESS, 1985. 109p.

FERREIRA, J. O corpo sígnico. In: ALVES, P.C.; MINAYO, M.C.S. (Org.). Saúde e doença. Um olhar antropológico. Rio de Janeiro: Fiocruz, 1994. 251p.

. Soigner les mal soignés. Ethnologie d'um centre de soins gratuits. Paris: L'Harmattan, 2004. 387p.

GERHARDT, T. E. Itinerários terapêuticos em situações de pobreza: diversidade e pluralidade. Cad. Saúde Pública, Rio de Janeiro, v.22, n.11, p.2449-2463, 2006.

LÉVI-STRAUSS, C. A eficácia simbólica. In: . Antropologia estrutural. Rio de Janeiro: Tempo Brasileiro, 1989. 456p. 
LIMA, J.C. et al. Desigualdades no acesso e utilização de serviços de saúde no Brasil. Saúde Debate, Rio de Janeiro, v.6, n.60, p.62-70, 2002.

LOMBRAIL, P. Accès aux soins. In: LECLERC, A. et al. (Org.). Les inegalités sociales de santé. Paris: Inserm, 2006. p.403-418.

KASSOUF, A.L. Acesso aos serviços de saúde nas áreas urbana e rural do Brasil. Rev. Econ. Sociol. Rural, Brasília, v.43, n.1, p.30-44, 2005.

LOYOLA, M.A. Médicos e curandeiros: conflito social e saúde. São Paulo: Difel, 1984. 198p. LUZ, M.T. Novos saberes e práticas em saúde coletiva: estudos sobre as racionalidades médicas e atividades corporais. São Paulo: Hucitec, 2007. 174p.

MASSÉ, R. Culture et santé publique. Les contribuitions de l'anthropologie à la prévention et à la promotion de la santé. Montreal: Gaëtan Morin Éditeur, 1985. 330p.

MEYER, D. Direitos reprodutivos e educação para o exercício da cidadania reprodutiva: perspectivas e desafios. In: FONSECA, C. (Org.). Antropologia, diversidade e direitos humanos. Porto Alegre: UFRGS, 1999. p.87-101.

MONTERO, P. Da doença à desordem: a magia na umbanda. Rio de Janeiro: Graal, 1985. 274p.

PINHEIRO, R.; GUIZARDI, F.L. Quando dádiva se transforma em saúde. Algumas questões sobre a integralidade e o cuidado nas relações entre sociedade e Estado. In: PINHEIRO, R.; MATTOS, R.A. (Org.). Cuidado: as fronteiras da integralidade. Rio de Janeiro: Cepesc, 2005. p.37-56.

RABELO, M. Religião e cura: algumas reflexões sobre a experiência religiosa das classes populares urbanas. Cadernos de Saúde Pública, Rio de Janeiro, v.9, n.3, p.316-325, 1993.

ROCHA, R. M. Trajetórias terapêuticas de usuários de serviços psiquiátricos e adeptos da umbanda: um estudo sobre pluralismo terapêutico. Rev. Enf. UERJ, Rio de Janeiro, v.8, n.2, p.73-77, 2000.

TRAVASSOS, C. et al. Desigualdades geográficas e sociais na utilização de serviços de saúde no Brasil. Ciência e Saúde Coletiva, Rio de Janeiro, n.5, p.133-149, 2000.

VALLA, V.V.; GUIMARÃES, M.B.; LACERDA, A. Religiosidade, apoio social e cuidado integral à saúde: uma proposta de investigação voltada para as religiōes populares. In: PINHEIRO, R.; MATTOS, R.A. (Org.). Cuidado: as fronteiras da integralidade. Rio de Janeiro: Cepesc, 2005. p.103-115.

VASCONCELOS, E. A priorização da família nas políticas de saúde. Saúde em Debate, v.23, n.53, p.155-172, 1999. 
${ }^{1}$ A pesquisa foi financiada pela Fundação de Amparo a Pesquisa do Estado do Rio de Janeiro (FAPERJ).

${ }^{2}$ Buscamos a perspectiva de Geertz (1989), na qual o antropólogo sempre realiza uma "interpretação de segunda mão".

${ }^{3}$ Expressão êmica para designar a manifestação da entidade religiosa no corpo do indivíduo. Sobre ritos de possessão nas religiōes afro-brasileiras, ver Dos Anjos (1995).

${ }^{4}$ Outros trabalhos já relataram como a dor é o principal sintoma reconhecido como doença (Ferreira, 1993 e 2004).

${ }^{5}$ Essas questões já foram demonstradas por inúmeros trabalhos, dentre eles, os clássicos Loyola (1984) e Montero (1985).

${ }^{6}$ Referimo-nos à noção de Eficácia Simbólica de Lévi-Strauss (1989), em que a cura se concretiza, pois o doente crê, e ele é membro de uma sociedade que crê.

${ }^{7}$ Os problemas de saúde, em ordem de freqüência, foram: hipertensão arterial sistêmica, diabetes melitus, cardiopatias, infarto agudo do miocárdio, acidente vascular cerebral, tireoidopatias, bronquite, broncopneumonias, problemas oculares e problemas de coluna vertebral.

${ }^{8}$ Dentre os locais citados por nossos entrevistados, estão: CSEGSF, IAPETEC, Fundão, Clínica de Fisioterapia Bonsucesso, Clínica São Camilo e São Carlos, Emergência Del Castilho, UPA Vila João, Hospital da Lagoa, Hospital Rocha Maia, Hospital Salgado Filho, Hospital Pedro Ernesto, Hospital do Andaraí, Hospital dos Servidores, Instituto de Cardiologia e Albano Reis, consultórios particulares e convênios de empresa.

${ }^{9}$ Em relação a críticas ao enfoque na família e questões reprodutivas do PSF, ver, por exemplo, Vasconcelos (1999) e Meyer (1999).

${ }^{10}$ As autoras participaram igualmente em todas as etapas da elaboração do artigo. 


\section{Abstract}

\section{The Paths to Healing: an anthropological approach about therapeutic itineraries of slum population of Manguinhos, Rio de Janeiro} This paper discusses the data of the survey conducted in 2008 in the Manguinhos Slum Complex, Rio de Janeiro, on therapeutic itineraries of the local population. By therapeutic itineraries we mean the paths taken by the individual in search of a solution to his/ her health problems. We aim to identify to what extent these paths are ordered by symbolic schemes or by the availability of resources. A qualitative method focused on the semi-directive interview technique, following an ethnographic script, was used. Three residents of each community of Manguinhos were interviewed, in a total of 26 interviews. The results show that the offer of services is heterogeneously distributed, being itself a generating factor of inequalities in disease. The different strategies show that the knowledge and practices of these individuals are made of, and due to different experiences, given biographic situations and that there is not a single model of Therapeutic Itinerary. The urban "marathons" ran by the local population denounce the urgency of the State to put into practice more fair political policies, with a full access to health care, thus ensuring the respect for the rights.

Key words: therapeutic itineraries, healing, religion, access to health, health services. 